\title{
Genotype-Phenotype Correlation in Patients Suspected of Having Sotos Syndrome
}

\author{
Lonneke de Boer ${ }^{a 1}$ Sarina G. Kant ${ }^{b 1}$ Marcel Karperien ${ }^{a, c}$ Lotte van Beers ${ }^{b}$ Jennifer Tjon ${ }^{c}$ \\ Geraldine R. Vink $^{b}$ Dewy van Tol ${ }^{b}$ Hans Dauwerse $^{b}$ Saskia le Cessie $^{d}$ Frits A. Beemer ${ }^{\mathrm{C}}$ \\ Ineke van der Burgt ${ }^{f}$ Ben C.J. Hamel ${ }^{f}$ Raoul C. Hennekamg, h Ursula Kuhnlel \\ Inge B. Mathijsseng Hermine E. Veenstra-Knoli Connie T. Schrander Stumpel ${ }^{\mathrm{j}, \mathrm{k}}$ \\ Martijn H. Breuning ${ }^{b}$ Jan M. Wit ${ }^{a}$ \\ a Department of Pediatrics, ${ }^{b}$ Center for Human and Clinical Genetics, ${ }^{c}$ Department of Endocrinology and Metabolic \\ Diseases and dDepartment of Medical Statistics, Leiden University Medical Center, Leiden; ${ }^{\mathrm{e} D e p a r t m e n t}$ of Clinical \\ Genetics, University Medical Center, Utrecht; ${ }^{f}$ Department of Human Genetics, University Medical Center Nijmegen, \\ Nijmegen; 9 Department of Clinical Genetics and hepartment of Pediatrics, Academic Medical Center, Amsterdam; \\ iDepartment of Clinical Genetics, Groningen Academic Hospital, Groningen; iDepartment of Clinical Genetics, \\ Academic Hospital Maastricht and kResearch Institute Growth and Development, Maastricht University, Maastricht, \\ The Netherlands, and 'Center for Child and Adolescent Health, Munich, Germany
}

\section{Key Words}

Sotos syndrome · NSD1 gene · Fluorescent in situ hybridization - Mutation analysis · Overgrowth syndrome

\begin{abstract}
Background: Deletions and mutations in the NSD1 gene are the major cause of Sotos syndrome. We wanted to evaluate the genotype-phenotype correlation in patients suspected of having Sotos syndrome and determine the best discriminating parameters for the presence of a NSD1 gene alteration. Methods: Mutation and fluorescence in situ hybridization analysis was performed on blood samples of 59 patients who were clinically scored into 3 groups. Clinical data were compared between patients with and without NSD1 alterations. With logistic regression analysis the best combination of predictive variables was obtained. Results: In the groups of typical,
\end{abstract}

1 These authors contributed equally to this work. dubious and atypical Sotos syndrome, 81, 36 and $0 \%$ of the patients, respectively, showed NSD1 gene alterations. Four deletions were detected. In 23 patients ( 2 families) 19 mutations were detected (1 splicing defect, 3 non-sense, 7 frameshift and 8 missense mutations). The best predictive parameters for a NSD1 gene alteration were frontal bossing, down-slanted palpebral fissures, pointed chin and overgrowth. Higher incidences of feeding problems and cardiac anomalies were found. The parameters, delayed development and advanced bone age, did not differ between the 2 subgroups. Conclusions: In our patients suspected of having Sotos syndrome, facial features and overgrowth were highly predictive of a NSD1 gene aberration, whereas developmental delay and advanced bone age were not.

Copyright $\odot 2004$ S. Karger AG, Basel

\section{Introduction}

Sotos syndrome, first described in 1964 [1], is an overgrowth syndrome characterized by pre- and postnatal accelerated growth with advanced bone age, mental retar-

Prof. Dr. J.M. Wit

Department of Pediatrics, Leiden University Medical Center PO Box 9600

NL-2300 RC Leiden (The Netherlands)

Tel. +31 71 5262824, Fax +31 71 5248198, E-Mail J.M.Wit@lumc.nl
Fax + 41613061234 E-Mail karger@karger.ch www. karger.com 
dation and distinctive facial features including macrocephaly, dolichocephaly, frontal bossing with a high hairline, a high palate and a prominent jaw [2]. In 2002 Kurotaki et al. [3] identified the NSD1 (nuclear receptor Suvar, 3-9, enhancer of zeste, trithorax domain protein) gene, and showed that haploinsufficiency of this gene is the major cause of the syndrome. Deletions mainly involving the NSD1 gene were found in a group of Japanese patients [3], and in studies in Europe [4-6] heterozygous intragenic mutations accounted for most of the Sotos syndrome phenotype.

In a British study [4], the majority of the mutations and deletions in the NSD1 gene were found in a group of patients with classical Sotos syndrome ( $76 \%$ of 37 patients). In a group of Sotos-like patients $(n=13)$ with atypical characteristics, especially concerning the facial features, 30\% showed a gene alteration in NSD1. Information about relations between genotype and clinical characteristics is limited [5-8]. Rio et al. [5] observed that macrocephaly and facial gestalt were consistent findings in a group with gene alterations in NSD1, whereas overgrowth and advanced bone age were not. Comparisons between patients with deletions and patients with mutations showed more severe mental retardation in the 6 patients with deletions. In another study [8] more central nervous system, cardiovascular and renal anomalies were found in patients with deletions. In a German study [6], no deletions were found but in $90 \%$ of the patients suspected of having Sotos syndrome a mutation was detected. Facial characteristics, overgrowth, macrocephaly and developmental delay correlated best with their molecular results.

In this study we aimed at a detailed comparison of clinical data, especially height, head circumference and bone age data at different ages, between patients with and without a NSD1 gene mutation or deletion. As in other studies [4-6] we categorized our patients. We used a clinical score to divide 59 patients, including 3 families, diagnosed as having or suspected of having Sotos syndrome into three categories ranging from typical to atypical Sotos syndrome. All were investigated for the presence of NSD1 mutations or deletions and we compared their growth patterns and other clinical characteristics. We addressed the following questions: (1) what are the differences in clinical and growth characteristics between patients with and those without NSD1 gene aberrations, and (2) which parameters have the highest predictive values for detecting an NSD1 gene aberration?

\section{Patients and Methods}

Clinical Analysis

This study was conducted with the prior consent of the Medical Ethical Committee of the Leiden University Medical Center and consent was given by the patients and/or their parents. Blood samples were obtained from 59 patients who were diagnosed as or suspected of having Sotos syndrome. Clinical and biochemical data of 31 of the patients were described in a previous study [9] and 28 were included later. Clinical data of the first 31 patients were studied and compared with the classical criteria [2] by an expert panel of 4 clinical geneticists (S.G.K., A.v.H., J.J.v.d.S., E.B.; see Acknowledgements) and a pediatric endocrinologist (J.M.W.). Patients were categorized into 3 groups: typical (group 1) Sotos syndrome; dubious (group 2), and atypical (group 3) Sotos syndrome. A clinical scoring system was developed which best reflected the panel's decisions on categorization of the patients (table 1) [9]. In short, in this clinical scoring system, marks were given for facial characteristics, growth, head circumference, bone age and development. The following facial characteristics were scored: antimongoloid slant of palpebral fissures; high palate; prominent jaw; dolichocephaly; frontal bossing, and high hairline. The maximum score on growth was given when the height standard deviation score (SDS) $[10,11]$ was above 2 for all measurements when corrected for target height SDS (gender corrected midparental height). In familial cases no correction for target height was made. A head circumference measurement above 2 SDS [11] gave a maximal score. A maximal score on bone age (2 marks) was given if at least one measurement was above 1.3 SDS (>p90) using the Greulich and Pyle method [12]. A maximal score on development was given when the measured IQ score was below 90 or developmental milestones were delayed. An IQ score of 90 corresponds with an SDS score of approximately -0.7. Patients with 9-11 marks were categorized as having typical Sotos syndrome, patients with 5-8 marks as dubious, and 1-4 marks as atypical Sotos syndrome. No patient with Weaver syndrome was included in this study. The 28 patients included later were categorized by the panel using the scoring system. Besides the clinical information used for scoring, additional information was collected on birth size parameters [13], body mass index (Quetelet index, weight $(\mathrm{kg}) /$ height $(\mathrm{m})^{2}$ ) [14], age at eruption of first teeth, occurrence of neonatal jaundice, feeding problems in the first year, hypotonia, strabismus, epilepsy, febrile convulsions, pes planus, scoliosis, cardiac anomalies, and brain anomalies seen on MRI or CT scan. One patient showed an additional marker chromosome consisting of the centromere and a small part of the long arm of chromosome 8 (patient 30) [9].

\section{Families}

Three families with more than 1 member showing characteristics of Sotos syndrome were included. The pedigrees are shown in figure 1.

Family $A$. The proband (patient 9; fig. 2A) was referred to the hospital at the age of 4 years with obesity and developmental delay. At birth and at the age of 4 years height, weight and head circumference were above the 97th percentile. Apart from slight facial features on physical examination, muscular hypotonia with poor coordination and clumsiness were found. Her sister (patient 38; fig. 2B) was 22 months old at the first visit with height, weight and head circumference above the 97 th percentile. More than her sister, she showed typical facial features of Sotos syndrome. Physical examination showed muscle hypotonia and clumsiness. The father's (patient 44)

\footnotetext{
$\overline{\text { Horm Res 2004;62:197-207 }}$
}

de Boer et al. 

cases.
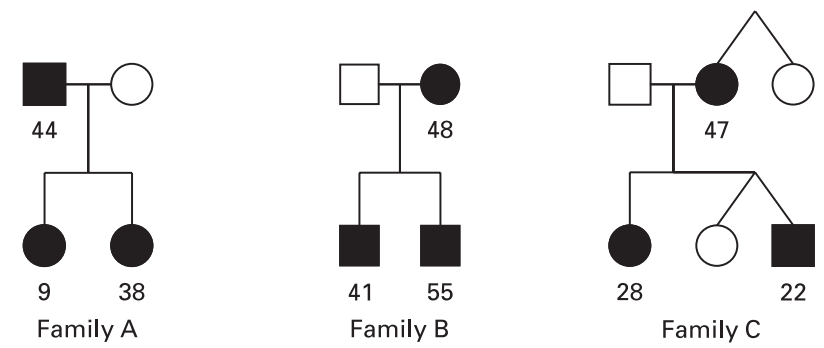

Fig. 1. Pedigrees of the 3 familial

Family B

Family C

Table 1. Clinical score for categorization of patients diagnosed as having Sotos syndrome

\begin{tabular}{lll}
\hline Criteria & & Marks $^{\mathrm{a}}$ \\
\hline Facial characteristics $^{\mathrm{b}}$ & 5 or 6 present & 5 \\
& 2,3 or 4 present & 3 \\
& 0 or 1 present & 0 \\
\hline Growth & Height SDS - TH SDS >2 (all measurements before final height) & 2 \\
& Height SDS - TH SDS $\leqslant 2$ (before final height is reached), but in past & 2 \\
& measurements $>2$ & 0 \\
\hline Bone age & Height SDS - TH SDS $\leqslant 2$ (all measurements before final height) & 2 \\
& $>$ P90 (at least one X-ray) & 1 \\
& Too old to measure bone age or = P90 & 0 \\
\hline Head circumference & $<$ P90 & 1 \\
& $<2$ SDS & 0 \\
\hline Development & IQ $<90$ or delayed developmental milestones & 1 \\
& IQ $\geqslant 90$ & 0 \\
\hline
\end{tabular}

$\mathrm{TH}=$ Target height.

a Sum 1-4 = Atypical Sotos syndrome; sum 5-8 = dubious Sotos syndrome; sum 9-11 = typical Sotos syndrome.

b Frontal bossing, high hairline, dolichocephaly, prominent jaw, high arched palate, antimongoloid slant of palpebral fissures.

height was $180 \mathrm{~cm}$, his birth length was $57 \mathrm{~cm}(3.3 \mathrm{SDS})$. No intelligence test was performed, but he seemed slow and worked as an unskilled laborer, whereas his brother and sister have completed high school and work as professionals.

Family B. The proband (patient 41 ; fig. 2C), the eldest son of this family, was suspected of having Sotos syndrome because of advanced bone age and developmental delay. He did not have all the typical facial characteristics of Sotos syndrome. Later his brother (patient 55) was also suspected because he had a large head circumference and behavioral problems. His IQ was in the normal range. The mother (patient 48; fig. 2D) was very tall (+2.6 SDS), and showed some facial characteristics of Sotos syndrome. She had never had learning difficulties.
Family $C$ (fig. 2E). The proband, a boy (patient 22) who is one of a set of dizygotic twins born after in vitro fertilization, was suspected of having Sotos syndrome at the age of 1.5 years; his head circumference was +3.5 SD and he showed delayed developmental milestones. His twin sister appeared normal. His elder sister (patient 28), also born after in vitro fertilization, was 4 years old at the time and had no enlarged head circumference, but showed some facial characteristics of Sotos syndrome. The mother (patient 47) was one of a set of dizygotic twins and childhood pictures showed facial characteristics of Sotos syndrome. She was very tall in childhood, but final height was in the normal range, and she had had some speech problems in childhood. Her twin sister showed no characteristics of Sotos syndrome. 

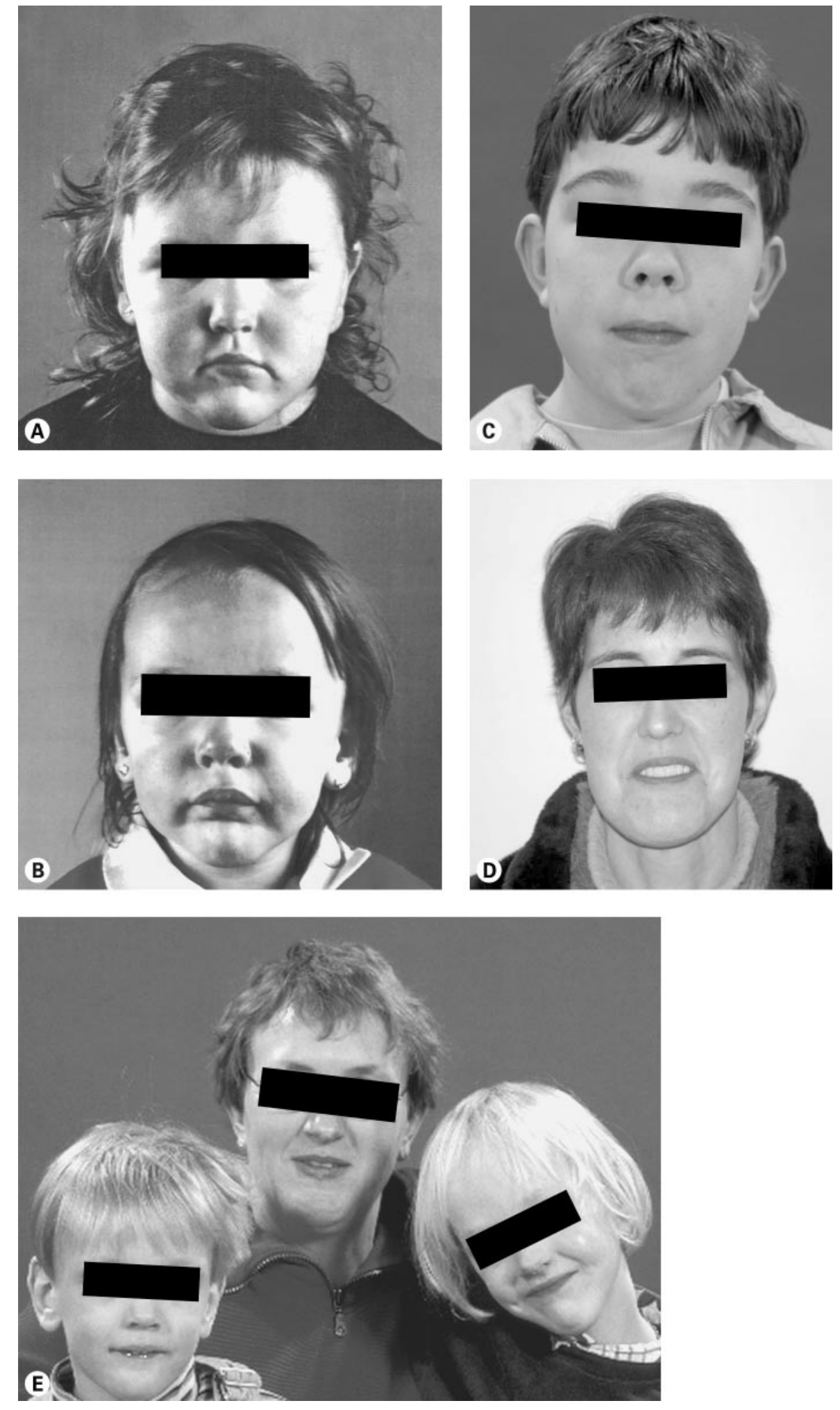

Fig. 2. Photographs of familial cases. A Patient 9 (family A). B Patient 38 (family A). C Patient 41 (family B). D Patient 48 (family B). E Patients 22, 28 and 47 (family C). 


\section{Deletion Analysis}

Fluorescence in situ hybridization (FISH) was performed as described previously [15]. Deletion detection was performed by hybridizing the PAC clone RP1-251c21 [3], visualized in red, simultaneously with the control probe RP1-179p12 (5q23.2), visualized in green. To trace the parental origin of the deletion, a PCR-based microsatellite analysis using three markers located within the common deleted region (BV005165, BV005168, D5S2111) was carried out.

\section{Mutation Analysis}

Blood samples from the probands and their parents were obtained and genomic DNA was isolated from EDTA anticoagulated blood by a salting-out procedure. The 22 coding exons of the NSD1 gene (exons 2-23) of the index patients were amplified by PCR using 34 primer pairs (a list available on request). PCR products were purified using the MultiScreen Assay System (Millipore, Billeria, Mass., USA) or the Qiagen Qiamp PCR Purification kit (Westburg, Leusden, the Netherlands) and directly sequenced on both strands on an ABI PRISM 3730 DNA Analyzer (Applied Biosystems, Foster City, Calif., USA) using the BigDye Terminator chemistry according to the manufacturer's instructions (Applied Biosystems). Mutations were considered pathogenic if they were likely to result in premature truncation of the protein. In case a variant was detected with unknown clinical significance, parental DNA was analyzed for the specific sequence variation. When the variant was absent in both parents and the parents had no sign of Sotos syndrome, the variant was considered pathogenic. To decide whether a variant with unknown clinical significance was likely to be pathogenic, in case no parental DNA was available, its position in the NSD1 gene, the corresponding amino acid change and the absence in other patients or controls were considered.

\section{Statistical Analysis}

Variables were compared between groups using the Student's t test or the $\chi^{2}$ test, whichever was appropriate. Logistic regression was used to find the combination of the most predictive variables for having a NSD1 gene alteration, which was translated into an adjusted clinical score. The discriminating performance of this score was computed. This included constructing a receiver-operating characteristics (ROC) curve with the computed area under the curve (AUC), positive likelihood ratio, negative likelihood ratio, positive predictive value, and negative predictive value at the optimal cutoff limit. Repeated measures analysis, using a linear mixed model, was used to compare bone age SD scores and growth characteristics over time between the groups. A $p$ value of $<0.05$ was considered significant.

\section{Results}

In table 2 the clinical scoring and presence of a NSD1 gene mutation or deletion are listed for each patient. Percentages of NSD1 gene aberrations in groups 1, 2 and 3 were 81,36 and $0 \%$, respectively.

\section{Deletions}

With FISH analysis, we found a deletion in one of the copies of the NSD1 gene in 4 patients. Two deletions were of paternal origin (patient 16, DNA of both parents available, and patient 35 , only maternal DNA available) and one deletion of maternal origin (patient 19 , only maternal DNA available). For patient 4 the DNA of the parents was not available. Two patients were categorized in group 1 (patients 4 and 16) and in group 2 (patients 19 and 35).

\section{Mutations}

The DNA of 55 patients was screened for NSD1 mutations by sequencing. In 23 patients, including 3 families, 19 different mutations were found. The mutations are listed in table 3 and include a splicing defect, missense $(\mathrm{n}=8)$, nonsense $(\mathrm{n}=3)$ and frameshift $(\mathrm{n}=7)$ mutations. In 2 families missense mutations were found and are discussed below. For the other 6 missense variants, the parental DNA of both parents could be tested and the mutation occurred de novo, therefore these were considered pathogenic.

\section{Families}

Family $A$. The father and both daughters were carriers of a missense mutation 5737A $>$ G, N1913D. This mutation is located in a conserved residue of the SAC (SET associated Cys-rich) domain and was therefore considered pathogenic. The proband was categorized into group 1; her sister and father into group 2 .

Family B. In the DNA of the mother and eldest son the missense variant $607 \mathrm{G}>\mathrm{A}, \mathrm{V} 203 \mathrm{I}$ was detected. The other son did not carry this variant. It was not located in a functional domain, the amino acid change did not lead to a change in polarity and in exon 2 no previous pathogenic mutations have been reported. Therefore this missense variant was considered nonpathogenic. The DNA of the grandparents was not available. The proband and the mother were categorized into group 2 and the brother into group 3.

Family $C$. In the DNA of the mother, daughter and son two missense variants were found, 6241T $>$ G, L2081V and $7576 \mathrm{C}>\mathrm{T}, \mathrm{P} 2526 \mathrm{~S}$, which were both not detected in the DNA of the mother's twin sister who showed no clinical characteristics of the syndrome. Nor was either one of these detected in any of the other patients. The first variant is located between the SET (su-var 3-9, enhancedzeta, trithorax) domain and the PHDIII (plant homeodomain) domain, and this variant was not detected in 58 controls. In contrast to the second variant, the amino acid change does not lead to a change in polarity. We assume that one of these mutations is pathogenic, but it is unclear which. The DNA of the grandparents was not available. All 3 family members were categorized into group 2 . 
Table 2. Clinical scores high to low for 59 patients diagnosed as having Sotos syndrome

\begin{tabular}{|c|c|c|c|c|c|c|c|c|c|c|c|c|c|c|c|c|}
\hline & Patient & Sex & Age, years & $\mathrm{Fac}$ & 1 & 2 & 3 & 4 & 5 & 6 & Gr & $\mathrm{Ba}$ & $\mathrm{Hc}$ & Dev & Sum & NSD1 \\
\hline \multirow{16}{*}{ Group 1} & 1 & $\mathrm{~F}$ & 4.3 & 5 & + & + & + & + & + & + & 2 & 2 & 1 & 1 & 11 & mut \\
\hline & 2 & $\mathrm{M}$ & 7.4 & 5 & - & + & + & + & + & + & 2 & 2 & 1 & 1 & 11 & mut \\
\hline & 3 & $\mathrm{M}$ & 17.8 & 5 & + & + & + & + & + & + & 2 & 2 & 1 & 1 & 11 & mut \\
\hline & 4 & M & 20.3 & 5 & + & + & + & - & + & + & 2 & 2 & 1 & 1 & 11 & del \\
\hline & 5 & $\mathrm{~F}$ & 1.5 & 5 & - & + & + & + & + & + & 1 & 2 & 1 & 1 & 10 & mut \\
\hline & 6 & $\mathrm{M}$ & 4.6 & 5 & + & + & - & + & + & + & 1 & 2 & 1 & 1 & 10 & - \\
\hline & 7 & M & 5.8 & 5 & + & + & + & + & + & + & 1 & 2 & 1 & 1 & 10 & - \\
\hline & 8 & $\mathrm{~F}$ & 18.9 & 5 & + & + & + & + & + & + & 1 & 2 & 1 & 1 & 10 & mut \\
\hline & $9^{\mathrm{A} 1}$ & $\mathrm{~F}$ & 4.0 & 3 & - & & + & - & + & - & 2 & 2 & 1 & 1 & 9 & mut \\
\hline & 10 & $\mathrm{M}$ & 4.5 & 3 & & + & & + & + & + & 2 & 2 & 1 & 1 & 9 & mut \\
\hline & 11 & $\mathrm{~F}$ & 5.7 & 5 & + & + & + & + & + & + & 1 & 1 & 1 & 1 & 9 & mut \\
\hline & 12 & $\mathrm{M}$ & 7.8 & 5 & + & - & + & + & + & + & 2 & 0 & 1 & 1 & 9 & mut \\
\hline & 13 & M & 8.5 & 5 & + & + & + & + & - & + & 0 & 2 & 1 & 1 & 9 & mut \\
\hline & 14 & M & 15.2 & 5 & + & + & + & - & + & + & 1 & 1 & 1 & 1 & 9 & mut \\
\hline & 15 & $\mathrm{M}$ & 15.3 & 3 & - & & + & + & - & - & 2 & 2 & 1 & 1 & 9 & - \\
\hline & 16 & $\mathrm{M}$ & 25.6 & 5 & + & + & + & + & + & + & 0 & 2 & 1 & 1 & 9 & del \\
\hline \multirow[t]{33}{*}{ Group 2} & 17 & $\mathrm{~F}$ & 3.3 & 3 & - & & + & + & & + & 2 & 2 & 0 & 1 & 8 & - \\
\hline & 18 & $\mathrm{M}$ & 3.5 & 5 & + & - & + & + & + & + & 1 & 0 & 1 & 1 & 8 & mut \\
\hline & 19 & $\mathrm{M}$ & 4.2 & 5 & + & + & + & + & + & + & 1 & 0 & 1 & 1 & 8 & del \\
\hline & 20 & M & 7.5 & 3 & + & & + & - & + & + & 1 & 2 & 1 & 1 & 8 & mut \\
\hline & 21 & $\mathrm{~F}$ & 33.4 & 3 & - & - & - & + & + & + & 1 & 2 & 1 & 1 & 8 & - \\
\hline & $22^{\mathrm{Cl}}$ & $\mathrm{M}$ & 2.1 & 5 & + & + & - & + & + & + & 0 & 0 & 1 & 1 & 7 & mut \\
\hline & 23 & $\mathrm{M}$ & 3.0 & 3 & - & - & - & - & + & + & 0 & 2 & 1 & 1 & 7 & mut \\
\hline & 24 & $\mathrm{M}$ & 3.8 & 3 & + & - & + & - & + & + & 0 & 2 & 1 & 1 & 7 & - \\
\hline & 25 & $\mathrm{M}$ & 4.1 & 3 & + & - & + & - & + & + & 1 & 2 & 0 & 1 & 7 & - \\
\hline & 26 & $\mathrm{~F}$ & 4.3 & 3 & + & - & - & - & + & & 2 & 2 & 0 & 0 & 7 & mut \\
\hline & 27 & $\mathrm{~F}$ & 4.4 & 5 & + & & + & + & + & + & 0 & 0 & 1 & 1 & 7 & mut \\
\hline & $28^{\mathrm{C} 2}$ & $\mathrm{~F}$ & 4.5 & 3 & + & - & + & - & + & + & 1 & 2 & 0 & 1 & 7 & mut \\
\hline & 29 & $\mathrm{M}$ & 4.9 & 5 & - & + & + & + & + & + & 0 & 0 & 1 & 1 & 7 & - \\
\hline & 30 & M & 5.6 & 3 & - & + & - & + & + & - & 0 & 2 & 1 & 1 & 7 & - \\
\hline & 31 & $\mathrm{~F}$ & 7.2 & 3 & - & + & + & - & + & + & 0 & 2 & 1 & 1 & 7 & - \\
\hline & 32 & $\mathrm{~F}$ & 9.2 & 3 & - & + & - & + & - & - & 0 & 2 & 1 & 1 & 7 & - \\
\hline & 33 & $\mathrm{M}$ & 20.6 & 3 & + & + & - & - & + & + & 0 & 2 & 1 & 1 & 7 & - \\
\hline & 34 & $\mathrm{M}$ & 33.5 & 3 & - & + & + & - & + & + & 1 & 1 & 1 & 1 & 7 & mut \\
\hline & 35 & $\mathrm{M}$ & 33.8 & 3 & + & & + & - & + & + & 0 & 2 & 1 & 1 & 7 & del \\
\hline & 36 & $\mathrm{~F}$ & 0.8 & 3 & - & - & - & + & + & + & 0 & 2 & 1 & 0 & 6 & mut \\
\hline & 37 & M & 1.8 & 3 & - & - & - & + & + & + & 0 & 2 & 0 & 1 & 6 & - \\
\hline & $38^{\mathrm{A} 2}$ & $\mathrm{~F}$ & 1.8 & 3 & + & & + & - & + & + & 2 & 0 & 1 & 0 & 6 & mut \\
\hline & 39 & $\mathrm{~F}$ & 4.8 & 3 & - & + & - & + & + & + & 1 & 0 & 1 & 1 & 6 & - \\
\hline & 40 & $\mathrm{~F}$ & 6.3 & 0 & - & & - & - & - & - & 2 & 2 & 1 & 1 & 6 & - \\
\hline & $41^{\mathrm{B} 1}$ & $\mathrm{M}$ & 10.7 & 3 & - & + & - & + & - & - & 0 & 2 & 0 & 1 & 6 & - \\
\hline & 42 & $\mathrm{~F}$ & 14.0 & 3 & - & + & + & - & + & + & 0 & 1 & 1 & 1 & 6 & - \\
\hline & 43 & $\mathrm{M}$ & 36.3 & 3 & - & + & - & - & + & + & 0 & 1 & 1 & 1 & 6 & - \\
\hline & $44^{\mathrm{A} 3}$ & M & 38.0 & 3 & - & & + & - & + & - & 0 & 1 & 1 & 1 & 6 & mut \\
\hline & 45 & $\mathrm{M}$ & 6.2 & 3 & - & + & - & - & + & + & 1 & 0 & 0 & 1 & 5 & - \\
\hline & 46 & $\mathrm{~F}$ & 10.2 & 0 & - & - & - & - & + & - & 1 & 2 & 1 & 1 & 5 & - \\
\hline & $47^{\mathrm{C} 3}$ & $\mathrm{~F}$ & 36.3 & 3 & - & - & + & - & + & - & 1 & 1 & 0 & 0 & 5 & mut \\
\hline & $48^{\mathrm{B} 3}$ & $\mathrm{~F}$ & 42.8 & 3 & + & + & + & - & - & - & 1 & 1 & 0 & 0 & 5 & - \\
\hline & 49 & $\mathrm{M}$ & 48.4 & 3 & - & + & + & - & - & - & 0 & 1 & 0 & 1 & 5 & - \\
\hline \multirow[t]{10}{*}{ Group 3} & 50 & $\mathrm{M}$ & 7.6 & 3 & - & - & + & - & + & - & 0 & 0 & 1 & 0 & 4 & - \\
\hline & 51 & $\mathrm{M}$ & 10.1 & 0 & - & - & - & - & - & - & 2 & 1 & 0 & 1 & 4 & - \\
\hline & 52 & $\mathrm{~F}$ & 11.5 & 3 & - & + & + & - & - & - & 0 & 1 & 0 & 0 & 4 & - \\
\hline & 53 & $\mathrm{M}$ & 12.8 & 0 & - & + & - & - & - & - & 2 & 0 & 1 & 0 & 3 & - \\
\hline & 54 & $\mathrm{~F}$ & 5.7 & 0 & - & + & - & - & - & - & 2 & 0 & 0 & 0 & 2 & - \\
\hline & $55^{\mathrm{B} 2}$ & $\mathrm{M}$ & 8.2 & 0 & - & + & - & - & - & - & 1 & 0 & 1 & 0 & 2 & - \\
\hline & 56 & M & 8.6 & 0 & - & - & - & - & - & - & 0 & 0 & 1 & 1 & 2 & - \\
\hline & 57 & M & 8.8 & 0 & - & - & - & - & - & - & 0 & 0 & 1 & 1 & 2 & - \\
\hline & 58 & M & 7.3 & 0 & - & - & - & - & - & - & 0 & 0 & 0 & 1 & 1 & - \\
\hline & 59 & $\mathrm{M}$ & 9.6 & 0 & - & - & - & - & - & - & 0 & 0 & 0 & 1 & 1 & - \\
\hline
\end{tabular}

Fac $=$ Facial characteristics $(1=$ down-slant palpebral fissures, $2=$ high arched palate, $3=$ prominent jaw, $4=$ dolichocephaly, $5=$ frontal bossing, $6=$ high hairline); $\mathrm{Gr}=$ growth; $\mathrm{Ba}=$ bone age; $\mathrm{Hc}=$ head circumference; $\mathrm{Dev}=$ development; mut = mutation; del = deletion. 


\section{Genotype-Phenotype Correlation}

For all the clinical and growth characteristics mentioned below a comparison was made between patients with deletions and patients with mutations and no significant difference was found. For subsequent genotype-phenotype correlations we divided all patients in 2 groups, either having a NSD1 gene aberration or not.

\section{Clinical Score}

In the group of patients in which NSD1 deletions or mutations were found, the total score and the subscores for facial characteristics and head circumference were significantly higher than in the group in which no NSD1 gene abnormalities were found (table 4). The subscores for growth and bone age were also higher, but the difference was not significant. The subscore for development was not different between groups. The percentages of patients with developmental delay were similar in both groups. Mean IQ scores for those tested were 75 in the group with mutations or deletions $(n=11)$ and 78 for the other group $(n=17)$. Bone age SD scores were compared in a repeated measures analysis and no overall statistical difference between the groups was detected $(p=0.46)$.
Also the patterns over time were similar (test for interaction between age and group yields, $p=0.14$ ). In figure 3 the difference between bone age and calendar age is shown as a function of calendar age.

\section{Predictive Variables for the Presence of a NSD1 Gene} Aberration

With an adjusted score, computed by logistic regression analysis, we determined the parameters with the highest predictive value for NSD1 gene alteration. Variables which showed univariate significance with a $\mathrm{p}$ value of 0.20 or lower were included in a logistic regression model with a backward selection procedure. The resulting prognostic score was: $-4.71(1.37)+1.26(0.74) \times($ downslant palpebral fissures $)+1.3(0.75) \times$ (pointed chin $)+$ $3.1(1.18) \times$ (frontal bossing) $+0.82(0.49) \times$ (growth score). The numbers between brackets are the standard errors. For simplification, numbers were rounded resulting in the following scoring system: Total score $=1 \times$ (down-slant palpebral fissures) $+1 \times$ (pointed chin $)+2 \times$ (frontal bossing) $+0.5 \times$ (growth score). The score for growth as mentioned in table 1 would be replaced by 0 , 0.5 or 1 mark. This means frontal bossing is the most

Table 3. NSD1 mutations found in 23 patients

\begin{tabular}{|c|c|c|c|c|c|}
\hline Exon & Mutation & AA Change & Name & Domain & Patient and comment \\
\hline 5 & $1427 \mathrm{~T}>\mathrm{A}$ & L476X & nonsense & - & 1 \\
\hline 5 & 1969insA & E675fsX & frameshift & - & 12 \\
\hline 5 & 2809delCGinsT & R937X & frameshift & - & 3 \\
\hline 5 & 3531 delT & F1177fsX1218 & frameshift & - & 8 \\
\hline 5 & 3550insT & E1184fsX & frameshift & - & 13 (also found by Douglas) \\
\hline 5 & $3680 \mathrm{~T}>\mathrm{G}$ & L1227X & nonsense & - & 5 \\
\hline 7 & $4108 \mathrm{C}>\mathrm{T}$ & Q1370X & nonsense & - & 34 \\
\hline 11 & 4548-4549delGGinsC & E1516fsX & frameshift & - & 2 \\
\hline 13 & 4912delCACA & H1638fsX & frameshift & - & 27 \\
\hline 14 & $5129 \mathrm{G}>\mathrm{A}$ & $\mathrm{C} 1710 \mathrm{Y}$ & missense & PHDII & 23 \\
\hline 16 & $5435 \mathrm{~T}>\mathrm{A}$ & V1812D & missense & PWWPI & 14 \\
\hline 18 & $5737 \mathrm{~A}>\mathrm{G}$ & N1913D & missense & SAC & family A \\
\hline 18 & $5740 \mathrm{C}>\mathrm{T}$ & $\mathrm{R} 1914 \mathrm{C}$ & missense & SAC & 20 \\
\hline 18 & $5885 \mathrm{~T}>\mathrm{C}$ & $\mathrm{I} 1962 \mathrm{~T}$ & missense & SET & 26 \\
\hline 19 & $5950 \mathrm{C}>\mathrm{G}$ & $\mathrm{R} 1984 \mathrm{G}$ & missense & SET & $\begin{array}{l}11(5951 \mathrm{G}>\mathrm{A}, \mathrm{R} 1984 \mathrm{Q}, \\
\text { found by Rio) }\end{array}$ \\
\hline 21 & $6241 \mathrm{~T}>\mathrm{G}$ & L2081V & missense (p?) & - & family $\mathrm{C}$ \\
\hline 23 & $6604 \mathrm{~T}>\mathrm{C}$ & $\mathrm{C} 2202 \mathrm{R}$ & missense & - & 36 \\
\hline 23 & $7576 \mathrm{C}>\mathrm{T}$ & $\mathrm{P} 2526 \mathrm{~S}$ & missense (p?) & - & family $\mathrm{C}$ \\
\hline 23 & $7618 \mathrm{delT}$ & S2540fsX & frameshift & - & 18 \\
\hline intron & IVS5+33A $>T$ & & splicing defect & & 10 \\
\hline
\end{tabular}

* p? = Pathogenic?, both mutations were detected in one family and it is not known which one is pathogenic. 
important characteristic, followed by the two other facial characteristics and overgrowth. The total score ranges from 0 to 5 . The AUC of the score from a constructed ROC curve was 0.88 , in comparison with 0.82 for the initial score. The optimal cutoff limit was a score of $\geq 3.5$. At this cutoff limit the positive likelihood ratio was 3.16 (confidence interval (CI) 1.79-5.59) and the positive predictive value 0.73 (CI 0.60-0.83). The negative likelihood ratio was 0.15 (CI 0.05-0.46) and the negative predictive value 0.89 (CI 0.72-0.96).

Fig. 3. Bone age (Greulich and Pyle method) - calendar age in years.

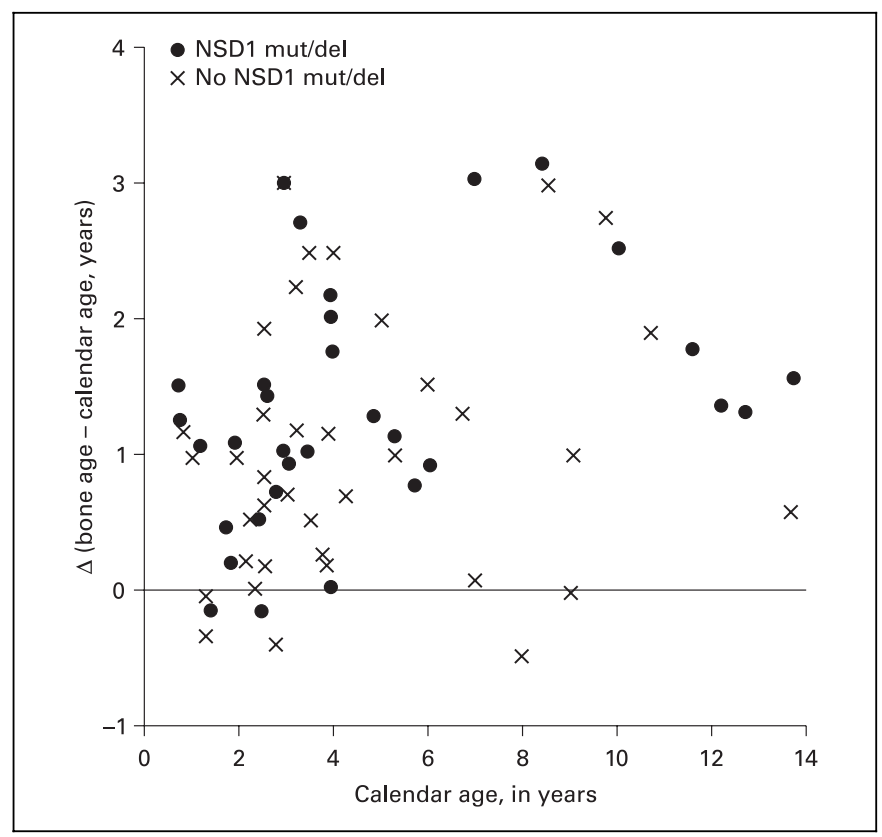

Table 4. Comparison of the clinical scores and clinical problems between patients with mutations or deletions in the NSD1 gene and those without

\begin{tabular}{|c|c|c|c|c|c|c|c|}
\hline \multirow[b]{2}{*}{ Total clinical score (mean) } & \multicolumn{3}{|c|}{$\begin{array}{l}\text { Group with NSD1 } \\
\text { mutation or deletion }(n=27)\end{array}$} & \multicolumn{3}{|c|}{$\begin{array}{l}\text { Group without NSD1 } \\
\text { mutation or deletion }(n=32)\end{array}$} & \multirow{2}{*}{$\begin{array}{c}\text { p value } \\
<0.001\end{array}$} \\
\hline & & 8.3 & & & 5.5 & & \\
\hline \multirow[t]{2}{*}{ Score facial characteristics } & 0 & 3 & 5 & 0 & 3 & 5 & \\
\hline & $0 \%$ & $44 \%$ & $56 \%$ & $31 \%$ & $69 \%$ & $9 \%$ & 0.001 \\
\hline Down-slanted palpebral fissures & & $67 \%$ & & & $19 \%$ & & $<0.001$ \\
\hline Higharched palate & & $52 \%$ & & & $56 \%$ & & 0.74 \\
\hline Prominentjaw & & $82 \%$ & & & $38 \%$ & & 0.001 \\
\hline Dolichocephaly & & $56 \%$ & & & $34 \%$ & & 0.11 \\
\hline Frontal bossing & & $96 \%$ & & & $50 \%$ & & $<0.001$ \\
\hline High hair line & & $85 \%$ & & & $44 \%$ & & 0.001 \\
\hline Sum 6 items (mean) & & 4.4 & & & 2.4 & & $<0.001$ \\
\hline \multirow[t]{2}{*}{ Score growth } & 0 & 1 & 2 & 0 & 1 & 2 & \\
\hline & $30 \%$ & $37 \%$ & $33 \%$ & $53 \%$ & $28 \%$ & $19 \%$ & 0.07 \\
\hline \multirow[t]{2}{*}{ Score bone age } & 0 & 1 & 2 & 0 & 1 & 2 & \\
\hline & $22 \%$ & $19 \%$ & $59 \%$ & $34 \%$ & $19 \%$ & $47 \%$ & 0.29 \\
\hline Score head circumference & & $89 \%$ & & & $63 \%$ & & $<0.05$ \\
\hline Score development & & $85 \%$ & & & $81 \%$ & & 0.69 \\
\hline Neonatal jaundice & & $58 \%$ & & & $36 \%$ & & 0.22 \\
\hline Feeding problems & & $86 \%$ & & & $35 \%$ & & $<0.01$ \\
\hline Hypotonia & & $68 \%$ & & & $59 \%$ & & 0.50 \\
\hline Strabismus & & $40 \%$ & & & $42 \%$ & & 0.88 \\
\hline Cardiac anomaly & & $21 \%$ & & & $0 \%$ & & $<0.01$ \\
\hline Epilepsy & & $0 \%$ & & & $7 \%$ & & 0.22 \\
\hline Febrile convulsions & & $29 \%$ & & & $13 \%$ & & 0.18 \\
\hline Scoliosis & & $17 \%$ & & & $21 \%$ & & 0.74 \\
\hline Pes planus & & $40 \%$ & & & $29 \%$ & & 0.48 \\
\hline Brain anomaly on CT scan & & $63 \%$ & & & $47 \%$ & & 0.48 \\
\hline Otitis & & $71.5 \%$ & & & $70.5 \%$ & & 0.96 \\
\hline
\end{tabular}


Table 5. Growth characteristics in mean standard deviation scores (SDS) of patients suspected of having Sotos syndrome

\begin{tabular}{llllllll}
\hline NSD1 & Birth & 0.5 years & 1 year & 2 years & 4 years & 10 years & Adult \\
\hline Height SDS & & & & & & \\
Mut/del & $1.90(\mathrm{n}=23)$ & $2.03(\mathrm{n}=15)$ & $2.47(\mathrm{n}=16)^{*}$ & $2.07(\mathrm{n}=19)$ & $2.58(\mathrm{n}=18)$ & $2.19(\mathrm{n}=5)$ & $0.94(\mathrm{n}=8)$ \\
No mut/del & $1.00(\mathrm{n}=25)$ & $1.49(\mathrm{n}=20)$ & $1.69(\mathrm{n}=23)$ & $1.81(\mathrm{n}=23)$ & $1.96(\mathrm{n}=26)$ & $1.96(\mathrm{n}=13)$ & $1.16(\mathrm{n}=8)$ \\
\hline Head circumference SDS & & & & & & \\
Mut/del & $1.52(\mathrm{n}=17)$ & $2.16(\mathrm{n}=15)$ & $2.61(\mathrm{n}=17)$ & $2.80(\mathrm{n}=19)$ & $2.72(\mathrm{n}=19)$ & $3.25(\mathrm{n}=6)$ & $2.77(\mathrm{n}=7)$ \\
No mut/del & $1.19(\mathrm{n}=24)$ & $1.80(\mathrm{n}=21)$ & $2.04(\mathrm{n}=22)$ & $2.24(\mathrm{n}=21)$ & $2.35(\mathrm{n}=23)$ & $2.88(\mathrm{n}=12)$ & $2.64(\mathrm{n}=7)$ \\
\hline
\end{tabular}

$* \mathrm{p} \leq 0.05$.

\section{Growth Characteristics}

Until the age of 10 years height SD scores are higher in the group with NSD1 gene alteration (table 5). A significant difference between the mean SD scores of length was found at the age of 1 year. Repeated measures analysis showed that the group with NSD1 gene alterations had a significantly larger length SDS (estimated difference 0.75 ; $95 \%$ CI $0.22,1.29$ ). The pattern over time did not differ significantly between the 2 groups (test for interaction between time and group, $p=0.86$ ). When a correction was made for target height SDS, no change in significance was found, height SDS was higher in the patients with NSD1 gene alterations at all ages. Head circumference SD scores also tended to be higher, but the difference was not significant (estimated difference $0.45 ; 95 \% \mathrm{CI}-0.025,0.92$; test for interaction between time and group, $p=0.06$ ). No significant difference was found in birth weight SDS, 0.54 $(\mathrm{n}=22)$ in the group with a mutation or deletion and 0.32 $(n=27)$ in the other group $(p=0.62)$. Body mass index did not differ significantly between groups.

\section{Clinical Problems}

Information on several clinical problems was compared between both groups (table 4). Significantly higher incidences were found for feeding problems in the first year and cardiac anomalies in the group with NSD1 gene alterations. Cardiac anomalies consisted of persistent ductus arteriosus, atrial septum defect, mitral insufficiency and coarctation of the aorta. One of these patients (patient 19) had a NSD1 deletion, and the others a mutation. Brain anomalies seen on CT scan were large ventricles. Age at the time of eruption of the first teeth in months was $6.1(\mathrm{n}=11)$ for the group with NSD1 mutations or deletions and $6.2(\mathrm{n}=14)$ for the group with no gene abnormalities $(\mathrm{p}=0.88)$.

Genotype-Phenotype in Sotos Syndrome

\section{Discussion}

Our study clearly showed that, using the clinical scoring system, high scores predicted the detection of a NSD1 mutation or deletion in patients suspected of having Sotos syndrome. Significant differences between patients with gene alterations of NSD1 and those without were found for higher length SDS in the former and a higher incidence of the following facial characteristics: antimongoloid slant of palpebral fissures; prominent chin; frontal bossing, and high hairline. Also a higher incidence of feeding problems and cardiac anomalies was found. The most important parameters for predicting NSD1 mutations or deletions in this study were frontal bossing, followed by antimongoloid slant of palpebral fissures, prominent jaw and overgrowth.

There is quite some variation between the ways of categorizing the patients in our study and 3 previously published studies [4-6]. Although 4 similar criteria were used in all studies, bone age ( $>1.3 \mathrm{SDS})$, growth ( $>2 \mathrm{SDS}$ ), head circumference ( $>2$ SDS) and dysmorphic facial features, development and congenital anomalies were not consistent criteria. Furthermore, the number of fulfilled criteria for inclusion in the different studies varied. We included patients if a diagnosis of Sotos syndrome was considered which resulted in the inclusion of patients with only one feature, whereas in other studies patients had to have more features. Both ways can result in a bias in the collection of patients. In our study height SDS was corrected for target height SDS, which was not done in other studies. NSD1 gene alterations were detected in $81 \%$ of our patients in the typical Sotos syndrome group. This percentage is comparable to the British study which reported 76\% [4]; the French study [5] reported 70\%, and a German study 90\% [6]. This high percentage of $90 \%$ could be due to the small size of their study group. Differ-

Horm Res 2004;62:197-207 
ences between the studies could also be due to the number of fulfilled criteria necessary for inclusion in the typical Sotos groups.

In the European studies the amount of deletions was small $(\mathrm{n}=3, \mathrm{n}=6$ and $\mathrm{n}=0)$ in 75,39 and 37 patients (4, 15 and 0\%) [4-6]. Deletions were also found in Sotos-like patients: $n=1$ [4] and $n=4$ [5]. We found 4 deletions (6\%): 2 in patients with typical and 2 in patients with dubious Sotos syndrome. This low percentage in European countries is in contrast to the high rate of deletions (67\%) observed in a study in Japan [3]. The difference is thought either to be attributable to patient selection bias or a population-specific genomic structure [16].

The locations of 2 mutations in our study have been described before. The frameshift mutation 3550insT, E1184fsX was detected earlier [4]. In our study a patient showed a missense mutation located in the SET domain: 5950C > G, R1984G. In another study [5] a patient with a missense mutation in the same amino acid was described as $5951 \mathrm{G}>\mathrm{A}, \mathrm{R} 1984 \mathrm{Q}$.

In accordance with others [17] the majority of the detected mutations are de novo and apparently there are no clear hot spots for mutations. Most missense mutations detected in our study are located in one of the functional domains. Three are not located in a functional domain. For 1 case, parental DNA did not show the mutation, therefore this mutation in exon 23 was considered pathogenic. The other 2 were found in 1 family (family $C$ ) and located in exons 21 and 23, respectively. It is not yet clear which of these mutations $(6241 \mathrm{~T}>\mathrm{G}$ or $7576 \mathrm{C}>\mathrm{T})$ is the pathogenic one. The DNA of the grandparents was not available.

Our observation in families $\mathrm{A}$ and $\mathrm{C}$ indicate that phenotypes can differ between patients with the same genotype. For example the 2 sisters in family A showed different facial characteristics. This suggests that interactions between NSD1 and other as yet undefined genetic or environmental factors may influence the expression of typical features of Sotos syndrome. We have one observation (patient 47) of less typical facial features in adulthood than in childhood.

Facial characteristics were also identified by others [5, 6] as consistent findings in patients with NSD1 gene alterations. In our study frontal bossing, followed by antimongoloid slant of palpebral fissures, prominent jaw and a high hairline were most predictive. A high hairline was highly associated with frontal bossing and therefore not found in the score developed by logistic regression analysis. Dolichocephaly and a high arched palate were less predictive, although for the last feature data were missing for 9 patients. In our study overgrowth was more extreme in the group with gene alterations of NSD1. Although cross-sectional data were used in our study, the overgrowth is seen especially in the first years of life as described before for a group of patients with suspected Sotos syndrome [18]. Mean SD scores were above 2 for ages between 0.5 and 10 years. The number of patients who have already reached final height is small in our study. Overgrowth was not a consistent finding in the French study [5]. Other studies [6, 8] pointed to overgrowth as an important predictor.

Advanced bone age in patients with gene alterations of NSD1 was not a consistent finding in other studies [5]. The mean bone age of all patients suspected of having Sotos syndrome was found to be advanced with no difference between patients with gene alterations of NSD1 and those without. In our study developmental delay was also not discriminatory because both groups showed the same percentage of patients with developmental delay. Both advanced bone age and delayed development are important findings for considering Sotos syndrome, but in the selected group of patients suspected of having Sotos syndrome they were not more extreme than in patients with mutations or deletions in the NSD1 gene.

Muscular hypotonia (68\%) or developmental delay could play a role in the higher incidence of feeding problems in the first year. In our study, a higher incidence of cardiac anomalies was found in the group with NSD1 gene alterations, although it should be noted that the number of patients was very small. Height SD scores of these patients where between +0.4 and +3.2 SDS. In contrast with a previous study [8] in which cardiac anomalies were exclusively found in patients with deletions, in our study anomalies were also found in patients with mutations. Other studies have compared patients carrying mutations with patients carrying deletions and found that patients with deletions have more severe mental retardation $[4,8]$ and less overgrowth. We compared all the parameters studied between these 2 groups, but could not find significant differences. However, one should note that our group of patients with deletions was very small.

Nowadays most patients suspected of Sotos syndrome will be screened for mutations or deletions in the NSD1 gene. The combination of the parameters with the highest predictive value for NSD1 gene alterations translated into a score could assist in deciding for mutation or deletion screening. No deletions or mutations were detected in our patients with a score below 2 and all patients with the maximum score of 5 showed gene alterations of NSD1. However, this score should be evaluated in a new group of 
patients. Furthermore it should be realized that the study group is a pre-selected group of patients with one or more of the clinical characteristics. In some typical Sotos patients, we did not detect alterations in NSD1. It is possible that they are carriers of genomic rearrangements in the NSD1 gene like small deletions and duplications that will not be detected by direct sequencing and FISH analysis as performed in our study.

In conclusion, in this study on genotype-phenotype correlations in patients suspected of Sotos syndrome, frontal bossing, pointed chin, down-slanted palpebral fissures and overgrowth were the most important predictive variables for having a gene alteration in one of the copies of the NSD1 gene. Besides detecting gene alterations in typical Sotos patients, mutations were also detected in some patients showing only one or a few characteristics.

\section{Acknowledgements}

We would like to thank: the patients and their parents for participating in the study; A. van Haeringen, J.J. van der Smagt and Mrs E. Bijlsma for help with classifying the patients, and the clinicians for providing clinical data, Mrs H.J. van der Kamp, A.G. Ketel, F.R. Langerijs, Mrs S.A. de Man, J.C. Mulder, R.A.A. Pelleboer, H.M. Reeser, J. Rehbock, B.J. Thio and G.J. van der Vlist. We gratefully acknowledge STINAFO (Dutch fund for disabled children) and Kassenaarfonds for their financial support.

\section{References}

$\checkmark 1$ Sotos JF, Dodge PR, Muirhead D, Crawford JD, Talbot NB: Cerebral gigantism in childhood. A syndrome of excessively rapid growth with acromegalic features and a nonprogressive neurologic disorder. N Engl J Med 1964;271: 109-116.

$\checkmark 2$ Cole TR, Hughes HE: Sotos syndrome: A study of the diagnostic criteria and natural history. $\mathrm{J}$ Med Genet 1994;31:20-32.

>3 Kurotaki N, Imaizumi K, Harada N, Masuno M, Kondoh T, Nagai T: Haploinsufficiency of NSD1 causes Sotos syndrome. Nat Genet 2003;30:365-366.

$\checkmark 4$ Douglas J, Hanks S, Temple IK, Davies S, Murray A, Upadhyaya M, Tomkins S, Hughes HE, Cole TR, Rahman N: NSD1 mutations are the major cause of Sotos syndrome and occur in some cases of Weaver syndrome but are rare in other overgrowth phenotypes. Am J Hum Gen 2003;72:132-143.

$\checkmark 5$ Rio M, Clech L, Amiel J, Faivre L, Lyonnet S, Le Merrer M, Odent S, Lacombe D, Edery P, Brauner R, Raoul O, Gosset P, Prieur M, Vekemans M, Munnich A, Colleaux L, CormierDaire V: Spectrum of NSD1 mutations in Sotos and Weaver syndromes. J Med Genet 2003; 40:436-440.

6 Turkmen S, Gillessen-Kaesbach G, Meinecke P, Albrecht B, Neumann LM, Hesse V, Palanduz S, Balg S, Majewski F, Fuchs S, Zschieschang P, Greiwe M, Mennicke K, Kreuz FR, Dehmel HJ, Rodeck B, Kunze J, Tinschert S, Mundlos S, Horn D: Mutations in NSD1 are responsible for Sotos syndrome, but are not a frequent finding in other overgrowth phenotypes. Eur J Hum Gen 2003;11:858-865.

7 Visser R, Matsumoto N: Genetics of Sotos syndrome. Curr Opin Pediatr 2003; 15:598-606. $\checkmark 8$ Nagai T, Matsumoto N, Kurotaki N, Harada N, Niikawa N, Ogata T, Imaizumi K, Kurosawa $\mathrm{K}$, Kondoh T, Ohashi H, Tsukahara M, Makita Y, Sugimoto T, Sonoda T, Yokoyama T, Uetake K, Sakazume S, Fukushima Y, Naritomi K: Sotos syndrome and haploinsufficiency of NSD1: Clinical features of intragenic mutations and submicroscopic deletions. J Med Genet 2003;40:285-289.

$>9$ de Boer L, Hoogerbrugge CM, van Doorn J, van Buul-Offers SC, Karperien M, Wit JM: Plasma insulin-like growth factors (IGFs), IGFbinding proteins (IGFBPs), acid-labile subunit (ALS) and IGFBP-3 proteolysis in individuals with clinical characteristics of Sotos syndrome. J Pediatr Endocrinol Metab 2004;17:615-627.

10 Fredriks AM, van Buuren S, Burgmeijer RJ, Meulmeester JF, Beuker RJ, Brugman E, Roede MJ, Verloove-Vanhorick SP, Wit JM: Continuing positive secular growth change in The Netherlands 1955-1997. Pediatr Res 2000;47:316-323.

11 Roede MJ, van Wieringen JC: Growth Diagrams 1980: Netherlands third nation-wide survey. Tijdschr Soc Gezondheidszorg 1985; 63(suppl):1-34.

12 Greulich WW, Pyle SI: Radiographic Atlas of Skeletal Development of the Hand and the Wrist. Stanford, Stanford University Press, 1959.

13 Niklasson A, Ericson A, Fryer JG, Karlberg J, Lawrence C, Karlberg P: An update of the Swedish reference standards for weight, length and head circumference at birth for given gestational age (1977-1981). Acta Paediatr Scand 1991;80:756-762.
14 Fredriks AM, van Buuren S, Wit JM, VerlooveVanhorick SP: Body index measurements in 1996-7 compared with 1980. Arch Dis Child 2000;82:107-112.

15 Dauwerse JG, Jumelet EA, Wessels JW, Saris JJ, Hagemeijer A, Beverstock GC, van Ommen GJ, Breuning MH: Extensive cross-homology between the long and the short arm of chromosome 16 may explain leukemic inversions and translocations. Blood 1992;79:1299-1304.

16 Kurotaki N, Harada N, Shimokawa O, Miyake N, Kawame H, Uetake K, Makita Y, Kondoh T, Ogata T, Hasegawa T, Nagai T, Ozaki T, Touyama M, Shenhav R, Ohashi H, Medne L, Shiihara T, Ohtsu S, Kato Z, Okamoto N, Nishimoto J, Lev D, Miyoshi Y, Ishikiriyama S, Sonoda T, Sakazume S, Fukushima Y, Kurosawa K, Cheng JF, Yoshiura K, Ohta T, Kishino T, Niikawa N, Matsumoto N: Fifty microdeletions among 112 cases of Sotos syndrome: Low copy repeats possibly mediate the common deletion. Hum Mutat 2003;22:378-387.

17 Kamimura J, Endo Y, Kurotaki N, Kinoshita A, Miyake N, Shimokawa O, Harada N, Visser R, Ohashi H, Miyakawa K, Gerritsen J, Innes AM, Lagace L, Frydman M, Okamoto N, Puttinger R, Raskin S, Resic B, Culic V, Yoshiura K, Ohta T, Kishino T, Ishikawa M, Niikawa N, Matsumoto N: Identification of eight novel NSD1 mutations in Sotos syndrome. J Med Genet 2003;40:e126.

18 Wit JM, Beemer FA, Barth PG, Oorthuys JW, Dijkstra PF, Van den Brande JL, Leschot NJ: Cerebral gigantism (Sotos syndrome). Compiled data of 22 cases. Analysis of clinical features, growth and plasma somatomedin. Eur J Pediatr 1985;144:131-140. 